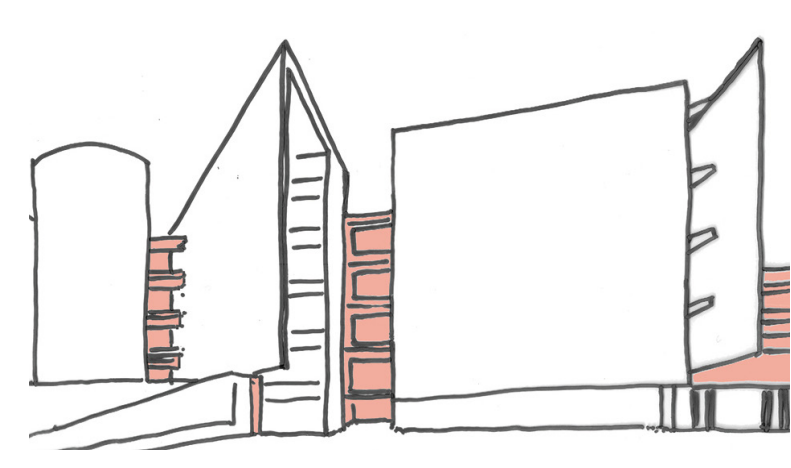

\section{O Sistema de Circulação como Estratégia Projetual. Análise do Projeto Espaço Natura de Roberto Loeb}

The circulation system as a design strategy. Analysis of the Natura Project designed by Roberto Loeb

Ana Tagliari e Wilson Florio*
*Docente e pesquisadora da Unicamp desde 2014. Atua na área de Teoria e Projeto de Arquitetura. Líder do Grupo "Arquitetura. Projeto, representação e análise" (CNPq/ Unicamp). Autora de artigos em revistas e eventos nacionais e internacionais.
${ }^{*}$ Docente e pesquisador da Graduação e Pós-Graduação da FAU Mackenzie e Unicamp. Líder do Grupo de Pesquisa "Arquitetura, Processo de Projeto e análise digital" (CNPq/Mackenzie). Autor de artigos em revistas e eventos nacionais e internacionais.

\section{Resumo}

Este artigo apresenta uma análise do Espaço Natura, de autoria do arquiteto Roberto Loeb, com foco no sistema de circulação. A premissa é que a circulação é parte integrante do programa de necessidades, e expressa conceitos fundamentais sobre a concepcão formal e espacial do projeto. A intenção é demonstrar estratégias projetuais que nortearam o projeto. Assim, a partir da apreciação do sistema de circulação foi possível identificar qualidades espaciais decorrentes da valorização dos percursos, internos e externos, das visuais e da relação espaço-tempo-movimento dos usuários. Os resultados obtidos revelam procedimentos adotados pelo arquiteto que tornaram possível ultrapassar as questões meramente funcionais de uma indústria.

Palavras-chave: Promenade Architecturale. Conceito. Visuais.

\section{Abstract}

This paper presents an analysis of Espaço Natura, designed by the architect Roberto Loeb, focusing on the circulation system. The premise is that circulation is an integral part of the architectural program, and expresses fundamental concepts about the formal and spatial design of the project. The intention is to demonstrate the design strategies that guided the project. Thus, from the appreciation of the circulation system, it was possible to identify spatial qualities resulting from the valorization of the internal and external paths, the visuals and the space-time-movement relation of the users. The results show procedures adopted by the architect that made it possible to overcome the merely functional activities of an industry.

Keywords: Promenade Architecturale. Concept. Visual. 


\section{Introdução}

Houve uma evolução entre o desenho inicial e o construído. (...) O tratamento dos espaços, com uma sucessão de surpresas, é completamente contrário à visão renascentista e, consequentemente, da arquitetura moderna brasileira, em que tudo se descortina de um ponto de vista. $\mathrm{O}$ desenho da Natura se desdobra em vários momentos, com surpresa. (Roberto Loeb, Revista Monolito n.25, 2015, p.22)

A

1. Esta pesquisa tem intenção de contribuir para o conhecimento nesta linha de análise com foco na circulação, como a de Marco Cezar Dudeque. Promenade Brasileira. Cadernos Pós. 2017; Mirian Keiko Ito Rovo de Souza Lima. A experiência do "passeio arquitetônico" nas obras de Severiano Porto. ArqUrb, 2014 e Ana Tagliari. Modelos conceituais de percurso e circulação no projeto de arquitetura. Revista 5\% Arquitetura + Arte, 2018.

usjt • arq.urb • número 24 | janeiro - abril de 2019
A metodologia adotada na pesquisa foi organizada a partir de: i) pesquisa bibliográfica; ii) levantamento de informações sobre o projeto; iii) visita técnica ao Espaço Natura; iv) análise do projeto por meio de desenhos e imagens; v) informações obtidas nas duas palestras que o arquiteto proferiu em 2017 em São Paulo (Figura 1).

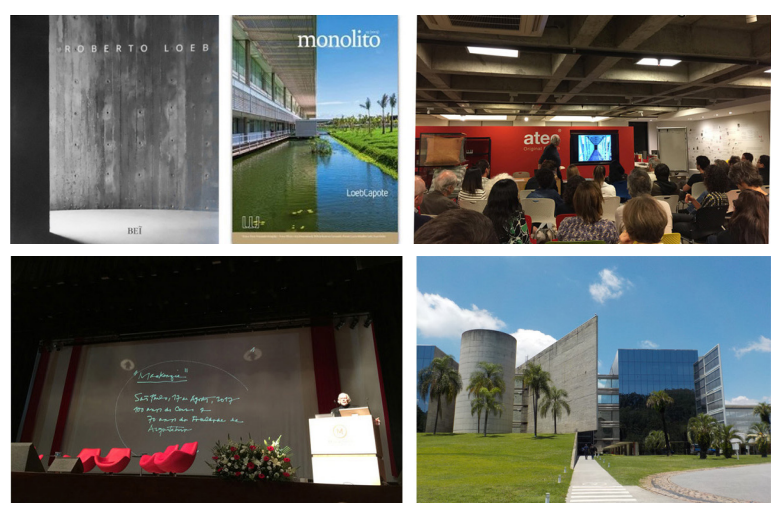

Figura 1. Capa do livro "Roberto Loeb" e Revista Monolito LoebCapote. Fotos das palestras proferidas pelo arquiteto Roberto Loeb ocorridas em 2017 (ATEC Cultural, 15 de maio e Mackenzie, 17 de agosto). Foto da visita realizada em 11/ 2017. Fonte: Fotos do autor, 2017. 
A pesquisa teve origem na preparação e discussões ocorridas durante as aulas de Projeto de Arquitetura na graduação, assim como do interesse de gerar material didático, envolvendo análise de projetos e o entendimento do partido arquitetônico a partir do sistema de circulação.

A ideia de se analisar "estratégias projetuais" se referencia nos escritos de Rafael Moneo (2004, p.2) que as define como "(...) mecanismos, procedimentos, paradigmas, e procedimentos formais que persistem nos trabalhos dos arquitetos, ferramentas que eles usam para dar forma às suas construções".

No âmbito da arquitetura, as decisões projetuais são tomadas a partir de diferentes fatores: funcional; conceitual; técnico-construtivo; estético-perceptivo. No caso de um projeto de uma indústria, os fatores que normalmente têm maior peso são o funcional e o técnico-construtivo. Entretanto, no caso da Indústria Natura, há um peso também para os fatores conceituais e estético-perceptivos.

Por outro lado, a volumetria de um projeto industrial normalmente é configurada por um monovolume, abrigando todas as funções e setores. Contudo, pode se notar que, especialmente em projetos mais recentes, Loeb tem se pautado por definir múltiplos volumes. A pulverização em blocos, setorizados a partir de sua especialização, implica diretamente em criar conexões externas que interligam tais blocos. Portanto, uma importante decisão arquitetônica e estratégia projetual é definir se o volume será único ou blocos separados e definidos por funções.

É importante notar que, no caso do Espaço $\mathrm{Na}$ tura, a topografia, a paisagem e as vistas são pontos de partida para as tomadas de decisões arquitetônicas. Desde o acesso principal até o interior de cada edifício que constitui o Espaço Natura, nota-se que a relação entre volumes fechados e abertos, entre circulações abertas e fechadas são estabelecidos procedimentos que levam em consideração a paisagem circundante e as sensações e percepções de bem-estar do usuário. Quando se observa o projeto de arquitetura, sobretudo a implantação, não é difícil notar que o arquiteto planejou, cuidadosamente, e por critérios claros e objetivos, a implantação de cada edifício diante da topografia e da vista circundante.

Diante deste quadro, é importante investigar quais foram as estratégias projetuais adotadas pelo arquiteto, implícita ou explicitamente, durante o processo de projeto. Este artigo tem como objetivo analisar tais estratégias, a fim de identificar o papel da circulação no projeto analisado, assim como a natureza das decisões arquitetônicas que consideram o bem-estar do usuário como aspecto central. 
A circulação como sistema chave para definição do partido arquitetônico

"A boa arquitetura 'se caminha' e 'se percorre' pelo interior e exterior. É a arquitetura viva." (Le Corbusier, 2005, p.43)

A análise de um projeto a partir de um olhar atento sobre o modo de organização do sistema de circulação pode revelar aspectos fundamentais sobre conceito, partido arquitetônico e estratégias projetuais adotadas pelo arquiteto.

Um bom projeto deve invariavelmente ter uma circulação bem resolvida, envolvendo aproximação ao edifício, acessos, percursos internos e externos, visuais, decorrentes de um conceito e um partido bem definido pelo arquiteto. No entanto, em arquitetura, a circulação não se basta como um sistema apenas funcional. A articulação dos ambientes e das visuais, assim como a valorização dos elementos da arquitetura, sensações, percepção e a apreciação dos espaços devem ser cuidadosamente orquestradas pelo arquiteto a partir de conceitos e condicionantes.

É plenamente possível analisar a circulação de um projeto a partir de critérios claros e objetivos, ou critérios conceituais. De modo objetivo, Francis Ching (2007) verifica que a circulação é parte de um sistema arquitetônico, que envolve espaço, estrutura, ambientes internos e externos, movimento no espaço-tempo, tecnologia, programa e um contexto. O movimento no espaço-tempo, para Ching, acontece em quatro etapas principais: aproximação e entrada; configuração do caminho e acesso; sequência de espaços; luz, vistas, tato, audição e olfato (percepção).

A aproximação a um edifício pode ser frontal, pela diagonal ou em espiral. Sua entrada pode ser marcada de diferentes maneiras, e com a articulação entre diversos elementos de arquitetura. Rampas, quando presentes, introduzem uma dimensão vertical no espaço, além de adicionar qualidade temporal ao ato de caminhar.

A configuração do percurso, que é definido no projeto, depende de diversos fatores: função, orientação, hierarquia, direcionamento, visuais, sensação, percepção, apreciação do espaço, simbolismo entre outros. Obviamente cada arquiteto interpreta o programa de acordo com seu repertório, fazendo com que cada projeto tenha seu partido definido a partir de olhar específico.

A investigação do tema circulação a partir de uma abordagem conceitual envolve também o entendimento de teoria, história e projeto. A organização do sistema de circulação dentro de um modelo conceitual moderno prevê um espaço amplo e desobstruído, onde o percurso pelo espaço faz com que o usuário tenha a compreensão do todo. O usuário domina o espaço pelo olhar num percurso livre. 
Numa abordagem diferente, dentro do conceito de pós-modernidade da arquitetura, o usuário é impelido a descoberta paulatina do espaço, caminhando por ele, com surpresas e descobertas graduais durante o percurso sequencial, quadro a quadro.

Os temas sobre movimento pelo espaço e a noção espaço-tempo foram amplamente debatidos em momentos da arquitetura moderna ao longo do século XX. A "quarta dimensão", o tempo, assim denominada por Bruno Zevi (1992), foi plenamente introduzida na arquitetura moderna como um meio de suplantar a arquitetura clássica, considerada estática. A estrutura independente, a criação de grandes vãos possibilitada pela técnica do concreto armado, fez com que os espaços se tornassem mais fluidos, favorecendo o pleno e constante movimento livre.

A ideia que os amplos espaços em arquitetura possam ser plenamente apreciados em movimento conduziu a ideia de passeio arquitetônico, ou como denominou Le Corbusier, "promenade architecturale". A partir de então, a partir da década de 1920, rampas e passarelas passaram a fazer parte dos espaços, permitindo exacerbar a ideia de passeio entre ambientes a partir de pontos de vista privilegiados no espaço.

Embora no século XIX o conceito francês de "parcours" fosse ensinado na Ècole des Beaux-Arts, como "trajeto de aproximação", ou um percurso, não havia nele a ideia de integração entre espa- ços. Foi o conceito de promenade architecturale que implicou em uma trajetória de circulação com livre disposição, axial, impelindo movimento dinâmico e assimétrico, cujo itinerário pudesse conduzir a uma variedade de perspectivas e pontos de vista.

No período que conhecemos como Arquitetura Pós-Moderna, o contextualismo foi uma denominação para aqueles arquitetos que desenvolviam projetos a partir de um estudo cuidadoso do entorno e sua história, e incorporavam estas condicionantes ao projeto do edifício. Um dos mais importantes arquitetos deste período foi James Stirling, que projetou e construiu o Staatsgalerie em Stuttgart (1977) na Alemanha. No texto "Graphic representation as reconstructive memory: Stirling's German Museum Projects", Gabriela Goldschmidt e Ekaterina Klevitsky analisam três projetos de Museus desenvolvidos por Stirling no mesmo período, onde o arquiteto adota o uso de axonométricas para estudar e representar a essência do projeto: o movimento e a circulação. O movimento e a circulação são prerrogativas do projeto contextualista de Stirling, que considera o edifício como parte integrante do tecido urbano, e a circulação a essência deste edifício. $O$ arquiteto cria espaços de circulação que naturalmente integram espaços internos e externos do edifício com a cidade.

Na contemporaneidade Rem Koolhaas é o arquiteto que muito expressa interesse e indagações 
pela questão da circulação em seus escritos e em seus projetos. $O$ elevador, que fragmenta e interfere na percepção e relação dos espaços, e a escada rolante, que conduz a um movimento contínuo e lento pelo espaço, são elementos de investigação conceitual para o arquiteto, que de certa maneira tem relação com a vida e cidade contemporânea (Koolhaas, 1999; 2010).

Assim, a partir da pesquisa realizada até o momento, pudemos identificar que há ao menos quatro modelos conceituais de percurso em arquitetura, que de maneira sintética e interpretativa pontuamos abaixo (Tagliari, 2018):

Modelo conceitual de circulação clássica Beaux-Arts: Marche. O movimento pelo edifício que faz o usuário perceber a enfilade, ou sequência e organização dos ambientes, geralmente compartimentados;

\section{Modelo conceitual de circulação na Arquitetu-} ra Moderna: apreciar o espaço como um todo, num sistema de circulação presente num espaço amplo, fluído e desobstruído;

Modelo conceitual de circulação no período da Pós-Modernidade: Os espaços e ambientes são descobertos de maneira a criar surpresas e descobertas, quadro a quadro, estimulando curiosidade e percepções;
Modelo conceitual de circulação na Arquitetura Contemporânea: A pluralidade e diversidade são características marcantes deste período. Portanto, identificamos uma mistura entre conceitos Modernos e Pós-Modernos na abordagem da circulação, unindo a fluidez e domínio do espaço da promenade com as descobertas quadro a quadro do período pós-moderno.

Tão importante como a configuração do sistema de circulação e a adoção, mesmo que intuitiva, de um dos modelos conceituais de percurso, a definição dos acessos também é uma questão importante no projeto. $\mathrm{O}$ acesso pode ter um caráter evidente e óbvio como na composição clássica ou discreto e não óbvio como na abordagem da arquitetura moderna e contemporânea.

Philip Johnson (1965, p.168) assim afirmou:

Certamente arquitetura não é projeto de espaço, certamente não é organização de massas e volumes. Estes são auxiliares para o ponto principal que é a organização da procissão. Arquitetura existe somente no tempo.

Esta afirmação nos leva a seguinte reflexão: arquitetura é dependente do sistema de circulação que nos conduz a diferentes percursos e percepções dentro e fora de um edifício. Logo se percebe que há íntimas relações entre espaço, tempo e movimento. $O$ deslocamento corpóreo pelo es- 
paço ao longo do tempo implica em diferentes direções do olhar. Se há íntimas relações entre o tempo e o modo de deslocamento pelo espaço é porque nossa visão é atraída por determinados pontos focais ou pontos de interesse, sobretudo causada por fortes contrastes - luz/sombra; aberto/fechado; transparência/opacidade; largo/ estreito; alto/baixo e assim por diante.

Os variados tipos de circulação propiciam diferentes modos de deslocamento e percepção do espaço. Circulações retilíneas conduzem a um campo de visão predominantemente frontal, enquanto que circulações curvilíneas conduzem a diferentes campos de visão ao longo do percurso. Este fato nos leva a concluir que cada tipo de circulação empregado pelo arquiteto implica em diferentes "leituras" e experiências do espaço.

Como será visto adiante, ao percorrer as circulações do Complexo Natura, nota-se que arquiteto planejou diferentes pontos focais ao longo dos percursos, e, ao mesmo tempo, alternou contrastes entre elementos materiais e imateriais, como os mencionados anteriormente.

\section{Roberto Loeb e o projeto do Espaço Natura}

Roberto Loeb, que hoje atua no escritório LoebCapote desde 2004, junto com Luis Capote, é arquiteto graduado na Universidade Mackenzie. Trabalhou para Rino Levi e Telésforo Cristofani antes de abrir seu próprio escritório na década de 1960.
O escritório é reconhecido por atuar em projetos complexos como indústrias, fábricas e complexos de edifícios com múltiplas funções como o Centro de Criatividade da IFF (2005-2009), o Centro administrativo Weishaupt (2006-2009) ou o Centro de distribuição da Avon (2998-2011), apenas para citar alguns.

Um dos principais projetos de arquitetura realizado nas últimas décadas no Brasil, segundo Fernando Serapião (Revista Monolito n.25, 2015, p.22), o Espaço Natura (1996-2001) está implantado num terreno de 750 mil metros quadrados, com 70 mil metros quadrados construídos, o conjunto na cidade de Cajamar, nos arredores da cidade de São Paulo, abriga indústria, escritórios e estoque. Segundo Serapião, o projeto do Espaço Natura estabeleceu um novo paradigma para as indústrias, por sua inovação na organização do programa de necessidades, soluções sustentáveis, humanização dos ambientes, e construção de alta qualidade.

O conceito adotado para o projeto expressa a marca Natura e sua filosofia, simbolizando transparência, respeito ao meio ambiente e acolhimento aos usuários. A partir deste conceito o complexo programa de necessidades foi formulado a partir das demandas da empresa. Segundo Silvana Rosso $(2011,128)$ as decisões se deram de forma compartilhada com a engenharia. $A$ técnica, o funcionamento indústria e a arquitetura desenvolveram-se em conjunto e em diálogo 
constante, resultando numa integração final bastante satisfatória. A obra tornou-se um exemplo de projeto sustentável no Brasil e no exterior. Em 2004, a convite da Natura, Loeb expôs o projeto em Zurique na Suíça na primeira edição do Holcim Fórum, simpósio para discussão sobre o futuro do meio ambiente construído, sendo o único representante da América Latina.

Roberto Loeb propôs um projeto diferenciado e inovador para a indústria com a adoção de iluminação natural, substituindo a solução tradicional de iluminação artificial, criando um ambiente de trabalho mais humano e confortável, além da economia de energia. Segundo Silvana Rosso (2011, p.15) a proposta é considerada inovadora até hoje. Os espaços fluidos, agradáveis, integrados à natureza e com amplas vistas, são ao mesmo tempo funcionais, pois favorece a logística da complexidade do programa, e também apresentam qualidades que ultrapassam apenas a funcionalidade. Após o projeto do Espaço Natura ser reconhecido pelas inovações, Loeb recebeu novas encomendas de projetos desta complexidade como o Centro de Tecnologia da Mahle, gerenciando não apenas o projeto de arquitetura, mas a obra, custos e cronograma, focando na eficiência e economia do processo como um todo.

Tradicionalmente a fábrica é um monobloco, uma caixa que cumpre uma série de objetivos de produção, administração e de funcionamento. Mas essa é uma visão apenas utilitária e funcional, que corresponde a uma proposta extremamente racional. $\mathrm{O}$ papel do arquiteto não é somente o de dar forma a um programa funcional. Ele é responsável por uma solução funcional que tenha sintonia com a pessoalidade. (LOEB, apud ROSSO, 2011, p.15)

A partir desta declaração, é plausível afirmar que, na visão do arquiteto, não basta atender às questões meramente funcionais e programáticas. Ao contrário, tudo indica que, a visão humanista, isto é, aquela que coloca o ser humano em primeiro lugar, tem primazia na definição do caráter e da qualidade dos espaços arquitetônicos. Assim as decisões arquitetônicas são norteadas por critérios qualitativos, que, por consequência levam em consideração as boas sensações causadas pelos espaços durante seu uso cotidiano.

$\mathrm{Na}$ atualidade, sabe-se que espaços bem ventilados, bem iluminados, não enclausurados, e conectados à natureza promovem o bem-estar dos usuários. São estas as qualidades notadas na visita realizada à Indústria Natura. São visíveis como os espaços foram planejados para gerar bem-estar das pessoas que ali realizam seus trabalhos diários. A passagem de um edifício ao outro é realizada de modo extremamente agradável, pois a paisagem circundante torna-se parte dos edifícios por meio das circulações.

Desde o projeto realizado, em 1971, para o Centro Administrativo Unibanco, nota-se a ênfase na relação entre espaços internos e externos. É visível o protagonismo das relações entre espaços internos e externos, e do paisagismo, na obra do 
arquiteto. A vegetação assume papel importante, uma vez que, junto às circulações, os variados percursos entre os edifícios fazem com que o usuário perceba a complementaridade entre edifícios e massa arbórea, e torna a visão de conjunto muito mais interessante.

As passarelas metálicas criadas para o Centro de processamento de dados do Unibanco em 1992 já prenunciavam sua preferência por circulações elevadas, que permitissem conexões e vistas privilegiadas a partir de percursos aéreos. Esta mesma estratégia é notada no projeto do Espaço Natura. Passarelas esculturais interligam os blocos, de modo a gerar diferentes percepções dos espaços circundantes.

Tanto as pontes metálicas envidraçadas, que conectam os blocos, como as passarelas metálicas soltas no interior dos edifícios, demonstram a intenção de gerar leveza visual e sensação de flutuação pelos espaços. Mais do que permitir vistas privilegiadas de espaços internos e externos, as passarelas e pontes funcionam como verdadeiros sistemas de articulação entre os edifícios.

\section{Análise do Projeto Espaço Natura com foco no sistema de circulação}

O conjunto de edifícios está implantado (Figura 2) à beira da rodovia Anhanguera, acomodado num terreno com declive próximo ao vale do Rio Juqueri. A conexão entre edifícios é realizada por meio de passarela ou ponte metálica, além de vencer a topografia da região, orienta e organiza a circulação e espacialização do complexo. O complexo de edifícios foi cuidadosamente desenhado para ser implantado de maneira harmônica em meio a mata nativa, rio, topografia, num ambiente contemporâneo, funcional e humanizado.

São 12 edifícios dotados de formas diferentes e interdependentes. Além da indústria, há laboratórios, espaços administrativos, depósitos, espaços de serviço e lazer aos usuários, e um sistema de circulação e estacionamento de automóveis e ônibus para atender a funcionalidade do complexo. Os blocos principais são: Edifícios de Pesquisa e desenvolvimento (P\&D), Núcleo de Aperfeiçoamento Natura (NAN), Portaria Social e entrada de visitantes, Fábricas e Clube para funcionários.

Os principais elementos de circulação, horizontal e vertical, identificados no complexo são: passarelas, galerias, ruas, passeios, corredores, caminhos, escadas, elevadores, rampas, pontes, vias, além dos acessos. Além disso, os materiais identificados foram: elementos metálicos, concreto aparente, vidro e madeira.

A visita tem início pelo edifício do NAN, que é composto por dois blocos: um de configuração mais quadrada que abriga o anfiteatro e outros ambientes do NAN; e outro retangular que abriga ambientes de trabalho. Os dois blocos são interligados por uma passarela fechada de concreto 


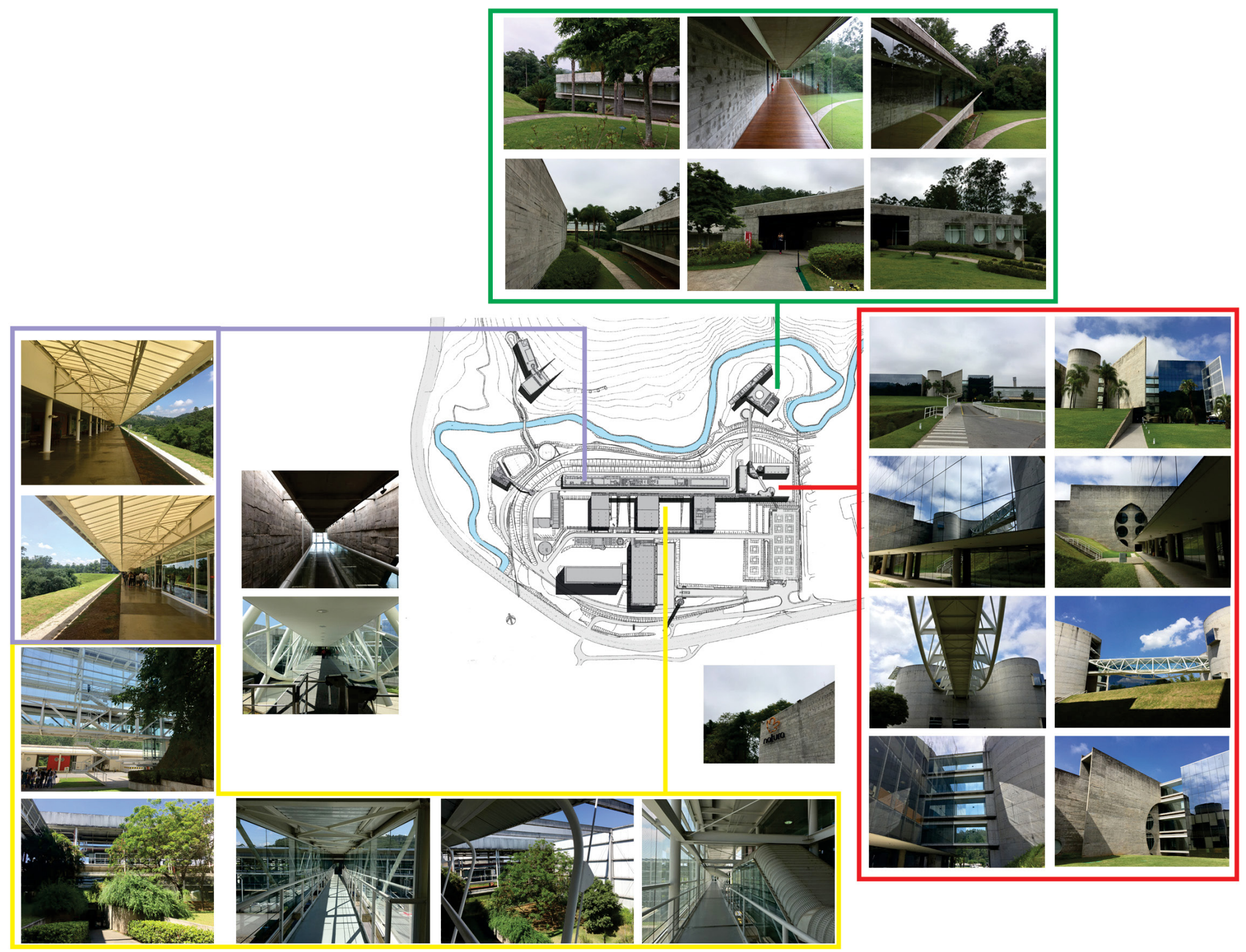

Figura 2. Fotos em torno do desenho de implantação retirado do livro Rosso, 2011. Legenda de cores: Verde: NAN; Lilás: Refeitório e Creche para funcionários; Amarelo: Fábrica; Vermelho: Administração e escritórios. Fonte: Fotos e montagem, Autor (2017) 
e vidro, que permite o usuário visualizar pontos focais dos dois blocos, além da paisagem circundante. Os outros edifícios que compõe o complexo Natura se localizam do outro lado do vale, interligado pela ponte metálica.

A aproximação dos usuários ao edifício do NAN (Figura 3) ocorre sobre um desenho de piso externo, que conduz a um acesso com configuração discreta, sem demarcação de porta, portal ou elementos desta natureza referencial. $O$ percurso revela, quadro a quadro, os ambientes do edifício. Após acessar, nos deparamos com um plano vertical curvo, que configura e resguarda o anfiteatro para apresentações do espaço interno.
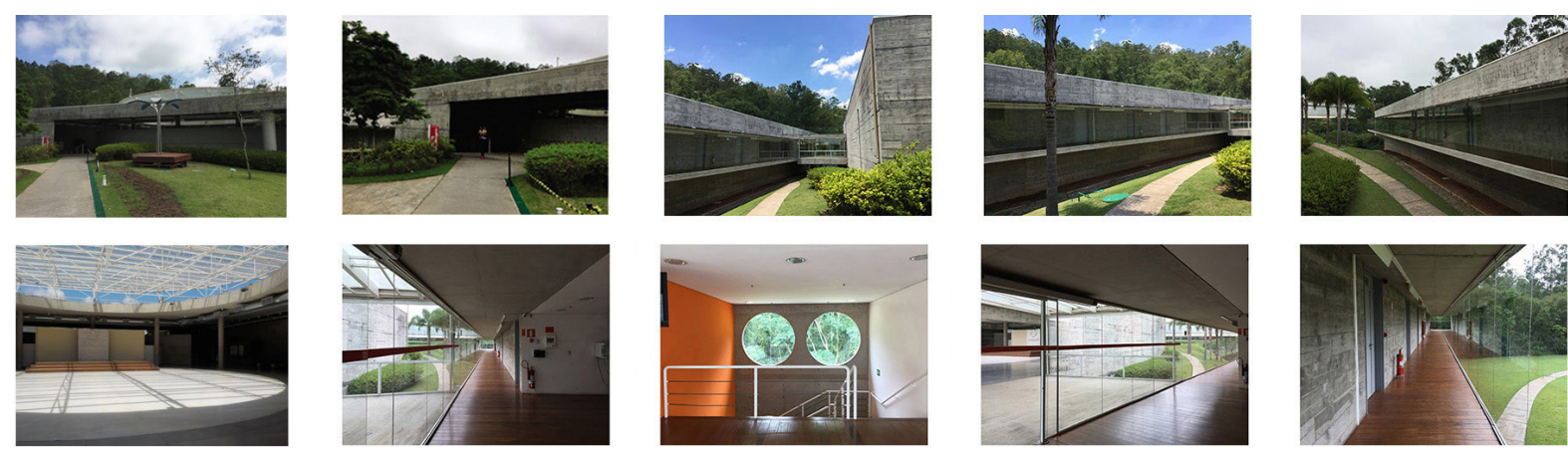

Figura 3. Fotos dos elementos e sistema de circulação do edifício NAN. Fonte: Fotos e montagem, Autor (2017)
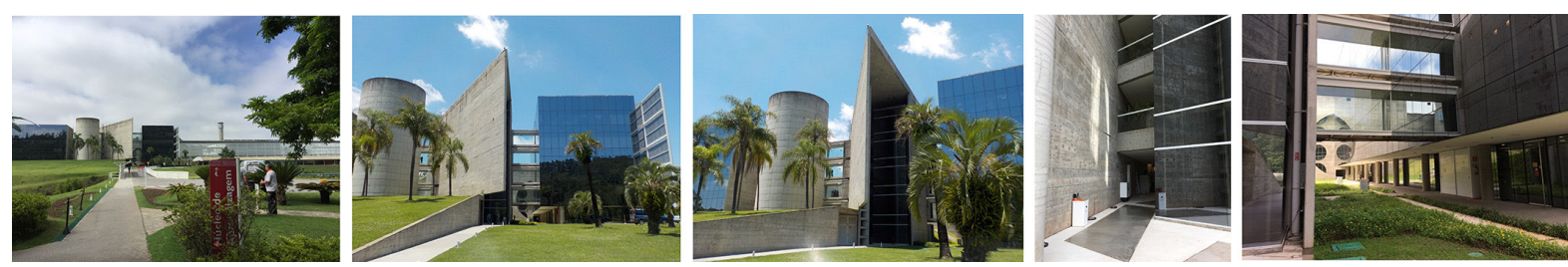

Figura 4. Fotos dos elementos e sistema de circulação do edifício de recepção e distribuição aos outros edifícios da Natura. Fonte: Fotos e montagem, Autor (2017) 
A partir deste ambiente de acolhimento inicial, configuram-se caminhos variados, com diferentes materiais e texturas. A recepção funciona como um ambiente distribuidor do sistema de circulação, uma vez que dali se desdobram caminhos horizontais e verticais, configurando um ponto de intersecção. É possível seguir para três diferentes destinos: o edifício de Pesquisa e Desenvolvimento de Produtos (P\&D), à Praça das Jabuticabeiras ou à própria fábrica. A partir da recepção, ainda no mesmo pavimento, pode-se seguir o percurso por um piso desenhado em concreto, iluminação natural indireta, destacando as irregularidades do material, proporcionando sensação de mistério, reflexão, surpresa e descoberta. Este caminho oferece acesso a um espaço externo, com uma escadaria aberta, que leva ao Pátio das Jabuticabeiras, um ambiente agradável e calmo. Acima é possível observar a passarela branca metálica, que conecta os edifícios de recepção (Figura 5).

A partir da recepção, um dos percursos acontece no primeiro pavimento, que pode ser acessado por uma escada ou por elevador. Por meio de uma ponte de estrutura metálica branca, com fechamento em vidro, ocorre a conexão entre a recepção e o edifício de P\&D. A partir das visuais deste percurso, pode-se observar o Pátio das Jabuticabeiras. $O$ acesso ao edifício de P\&D é restrito aos colaboradores, e tem acesso controlado, garantindo organização. As visuais oferecidas durante o percurso permite o contato visual com a natureza do espaço externo.
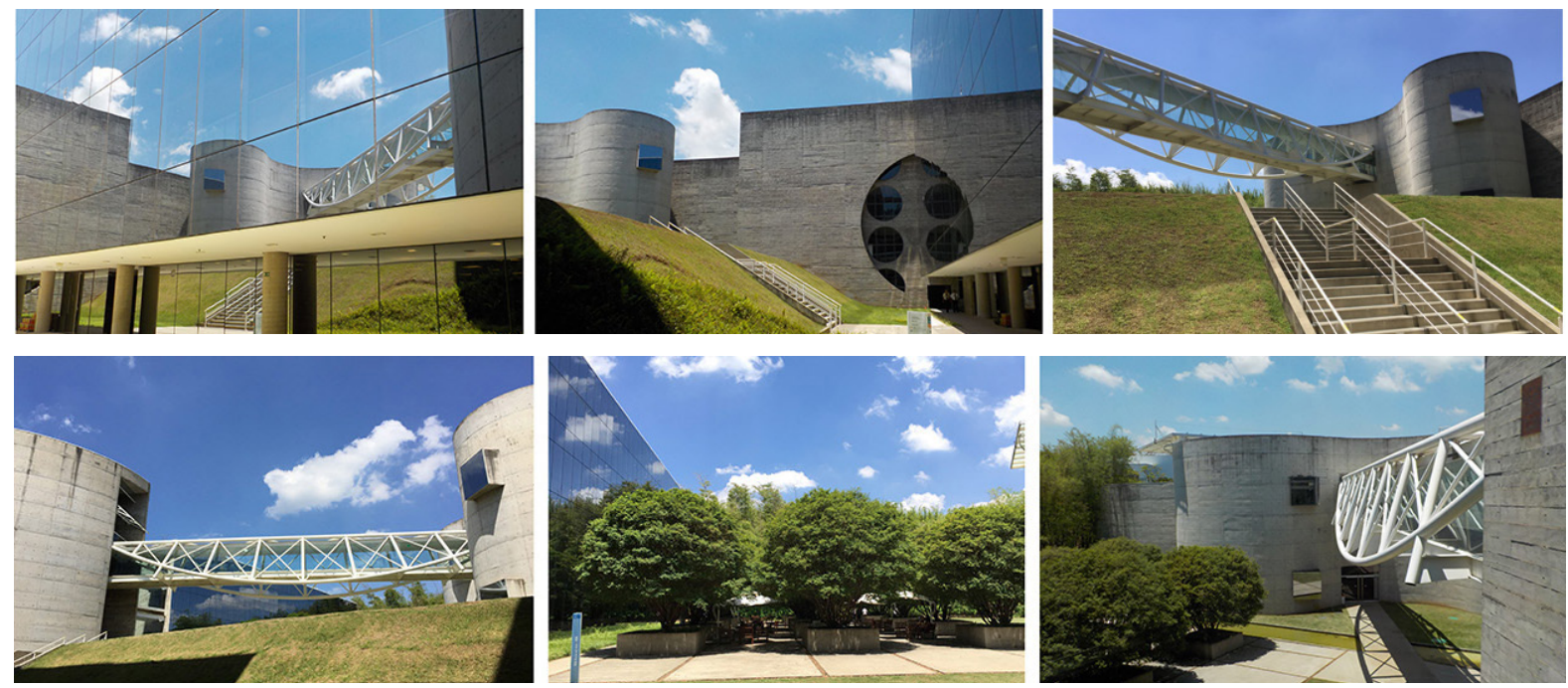

Figura 5. Fotos dos elementos de circulação do edifício de recepção e distribuição, P\&D, pátio das jabuticabeiras e ponte branca metálica. Fonte: Fotos e montagem, Autor (2017) 
A partir de um núcleo de circulação vertical localizado numa das extremidades do edifício de P\&D é possível acessar o sistema de circulação horizontal composto por passarelas metálicas, por onde é possível percorrer e observar as atividades nas fábricas. Neste percurso é possível visualizar os ambientes de trabalho da fábrica. Devido os fechamentos em vidro, por este percurso também é possível visualizar toda a paisagem de mata nativa do entorno, garantindo integração visual dos espaços e iluminação natural o dia todo (Figura 6).

Durante este percurso pode-se avistar a Praça das Pitangueiras, onde se localiza uma passarela, que conecta com o estoque da fábrica, proporcionando continuidade visual e espacial, sensação de calma e tranquilidade.
Após o percurso que permite a visualização das fábricas pode-se descer por uma escada que conduz à Praça das Pitangueiras, um ambiente agradável e acolhedor. Este ambiente está localizado num importante eixo de circulação horizontal e vertical que conecta o edifício das fábricas com o bloco de instalações de apoio aos funcionários com berçário e refeitório (Figura 7). Neste percurso final o usuário tem uma vista, cuidadosamente planejada, do vale, da natureza e também ao longe do edifício do NAN (Figura 8).

As visuais oferecidas nos percursos são cuidadosamente planejadas pelo arquiteto de modo a criar expectativas, surpresas e encanto. Deste modo, visuais da natureza circundante, ou do próprio complexo de edifícios, além das visuais que se configuram dos ambientes internos dos
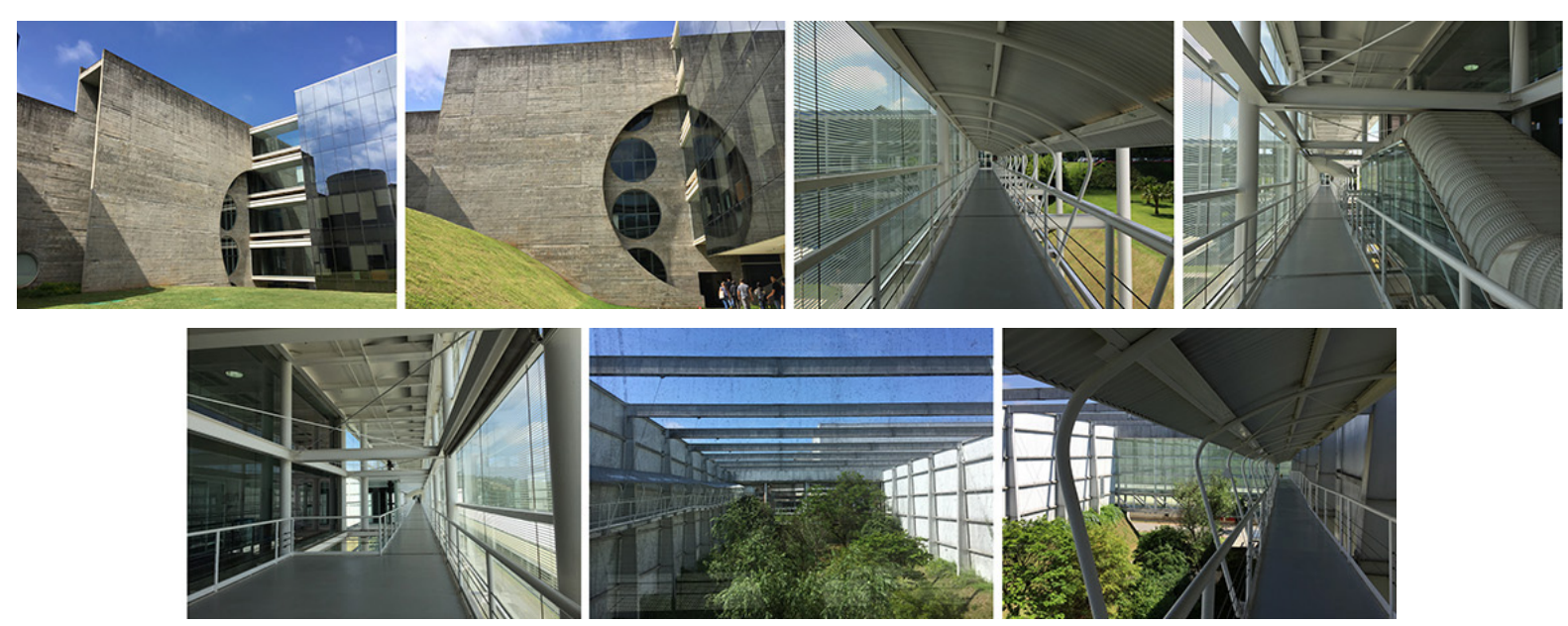

Figura 6. Fotos dos elementos e sistema de circulação para o percurso de visualização das fábricas e praça das pitangueiras. Fonte: Fotos e montagem, Autor (2017) 


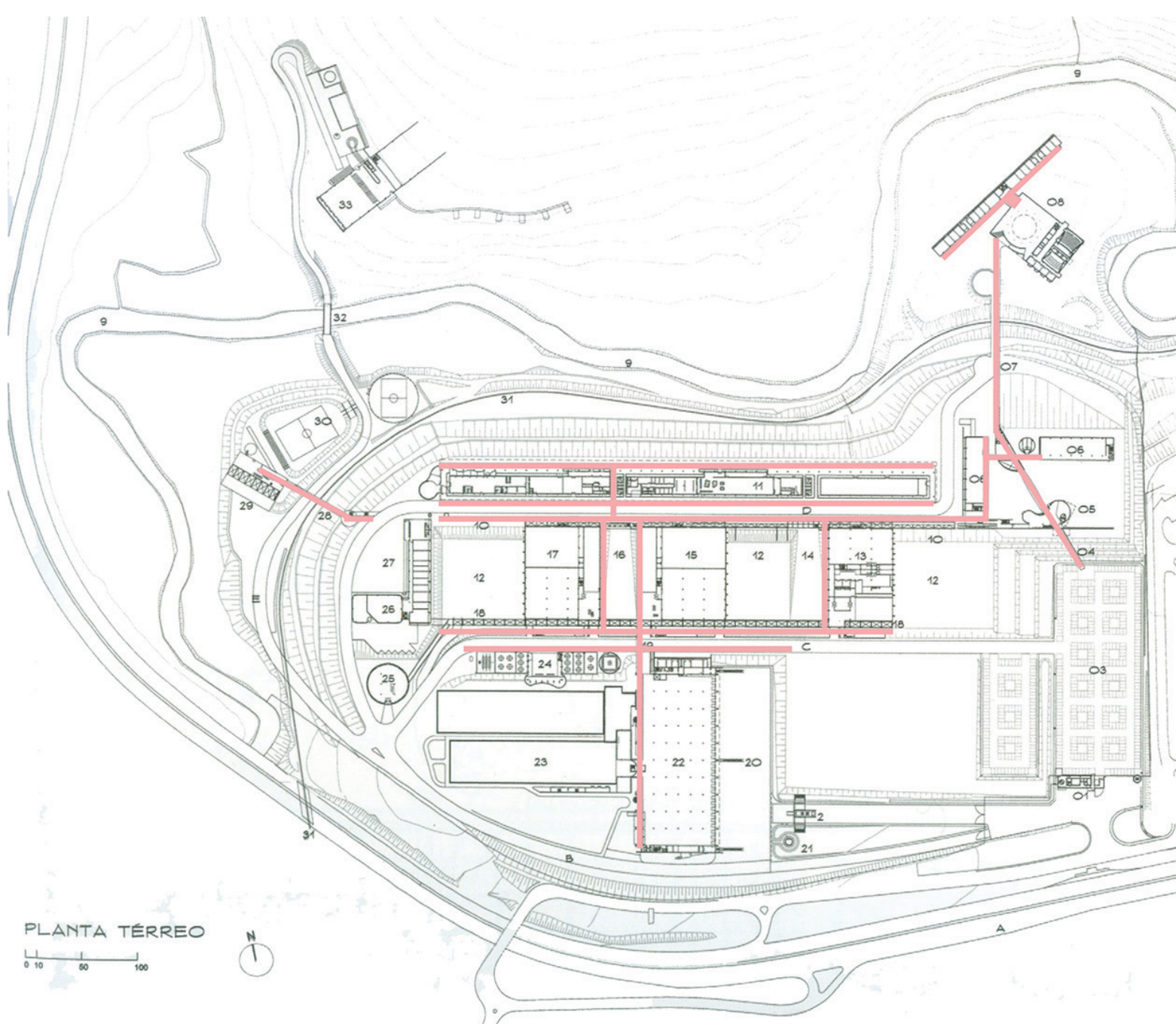

Figura 7. Implantação do complexo Espaço Natura com diagramas de circulação principal. Fonte: Diagrama, Autor (2017). Desenho, Rosso (2011).

usjt • arq.urb • número 24 | janeiro - abril de 2019 edifícios, tornam-se este "passeio arquitetônico" muito expressivo (Figura 9).

O trabalho intenso de composição com elementos materiais e imateriais (Figura 11), cheios e vazios, luz e sombra, brilho e escuro, transparência e opacidade, estimula as sensações e percepções do espaço de maneira positiva e enriquecedora, planejadas para situações com luz do dia ou da noite.

É notável como a configuração dos percursos depende da função, orientação, hierarquia, direcionamento, visuais, sensação, percepção, apreciação do espaço, simbolismo entre outros. A partir dos percursos planejados deste projeto, a sucessão de elementos visuais configura a composição harmônica entre arquitetura e paisagem. Consequentemente nota-se claramente que há um sistema de percursos que conectam espaços internos e externos, de modo integrado visual e espacialmente (Figura 10).

Verifica-se a integração dos espaços e ambientes por meio de pontes, passarelas e caminhos bem delimitados, configurando a circulação como sistema diferencial e preponderante do projeto, explorando a paisagem local, gerando sensações e surpresas a partir de pontos focais. Além disso, existem espaços de convivência, como a praça das jabuticabeiras, que objetiva o descanso e integração dos colaboradores, proporcionando a percepção de um ambiente humanizado e confortável. 

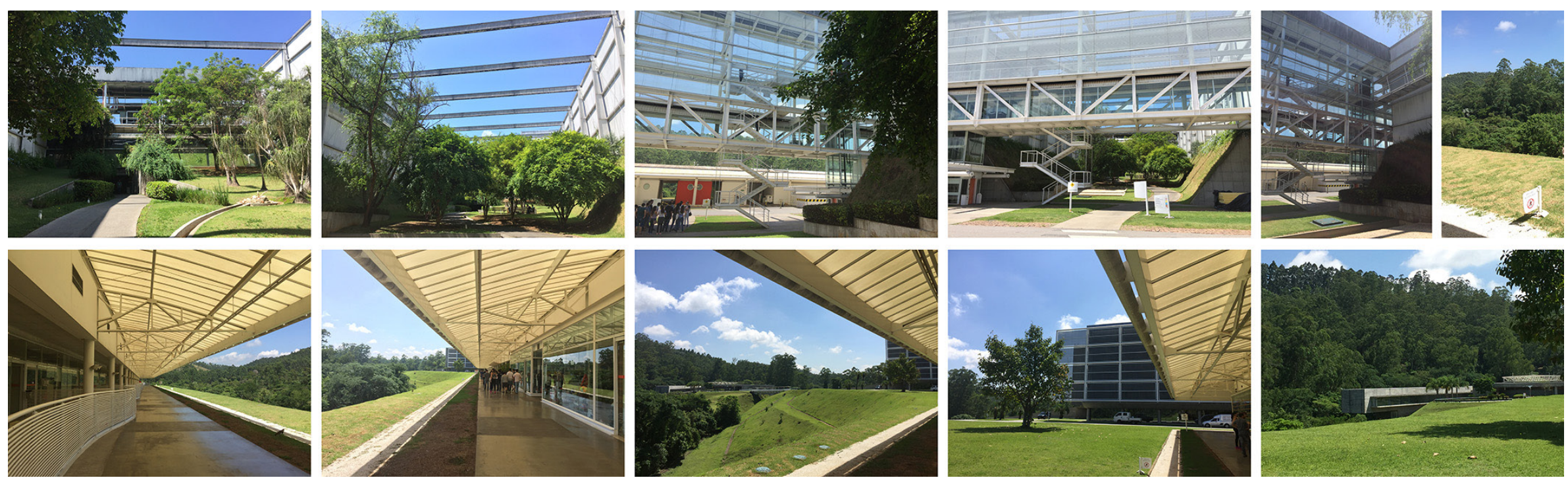

Figura 8. Fotos dos elementos e sistema de circulação no percurso da praça das pitangueiras e instalações de apoio aos

funcionários. Fonte: Fotos e montagem, Autor (2017).
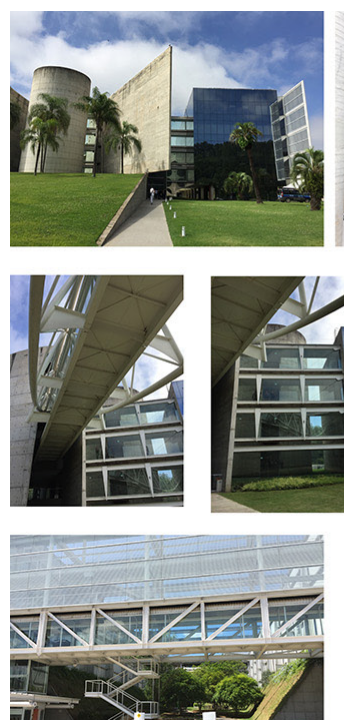
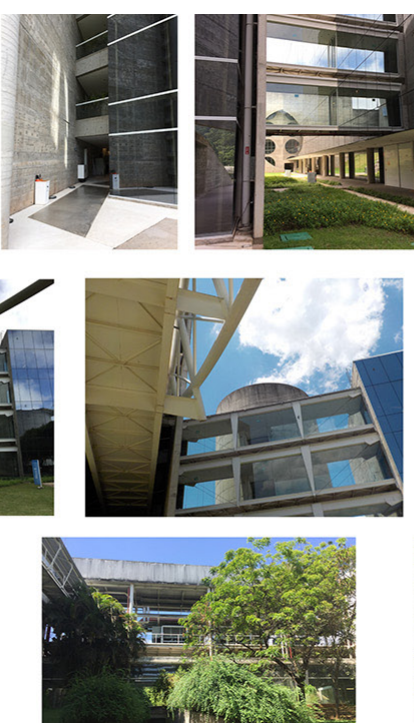
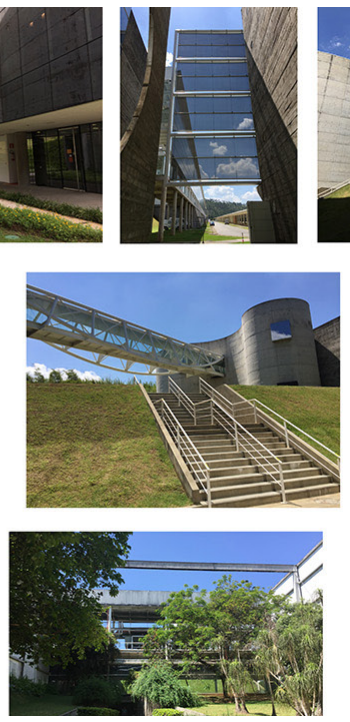
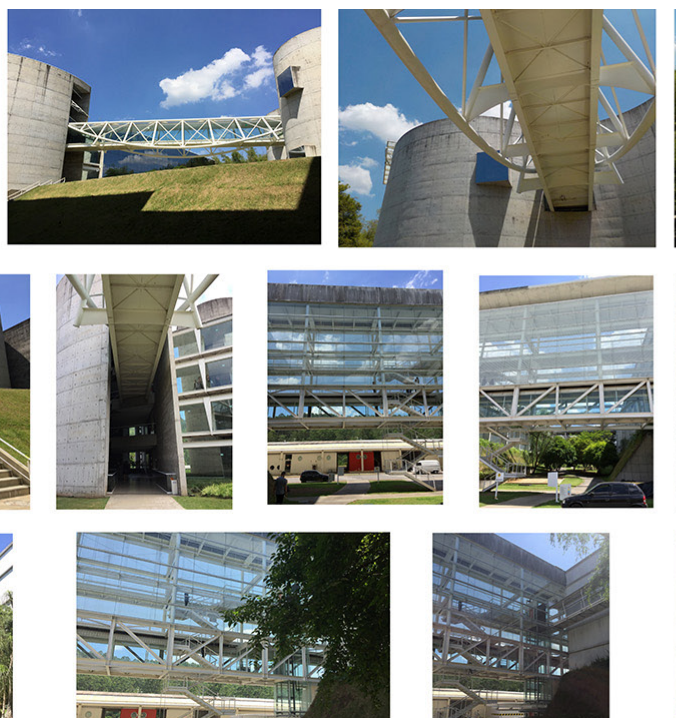
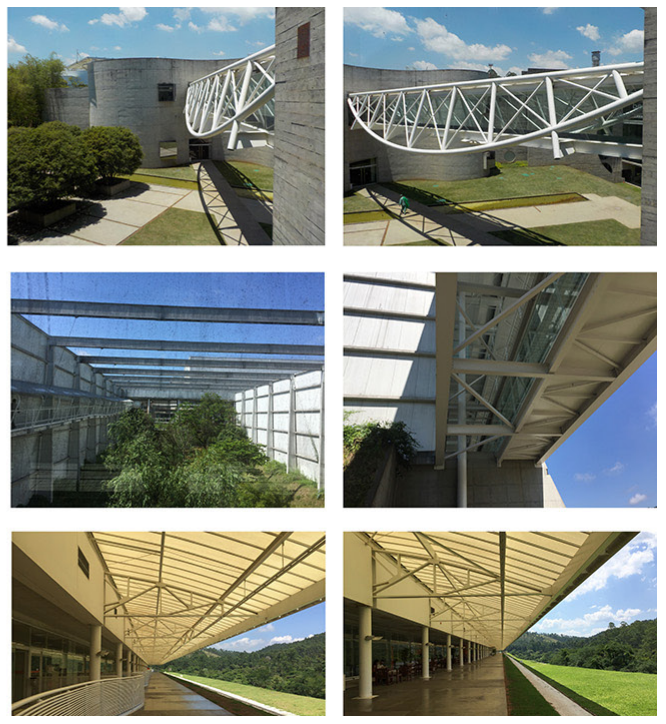

Figura 9. Fotos externas dos elementos de circulação dos edifícios do Espaço Natura. Fonte: Fotos e montagem, Autor (2017). 

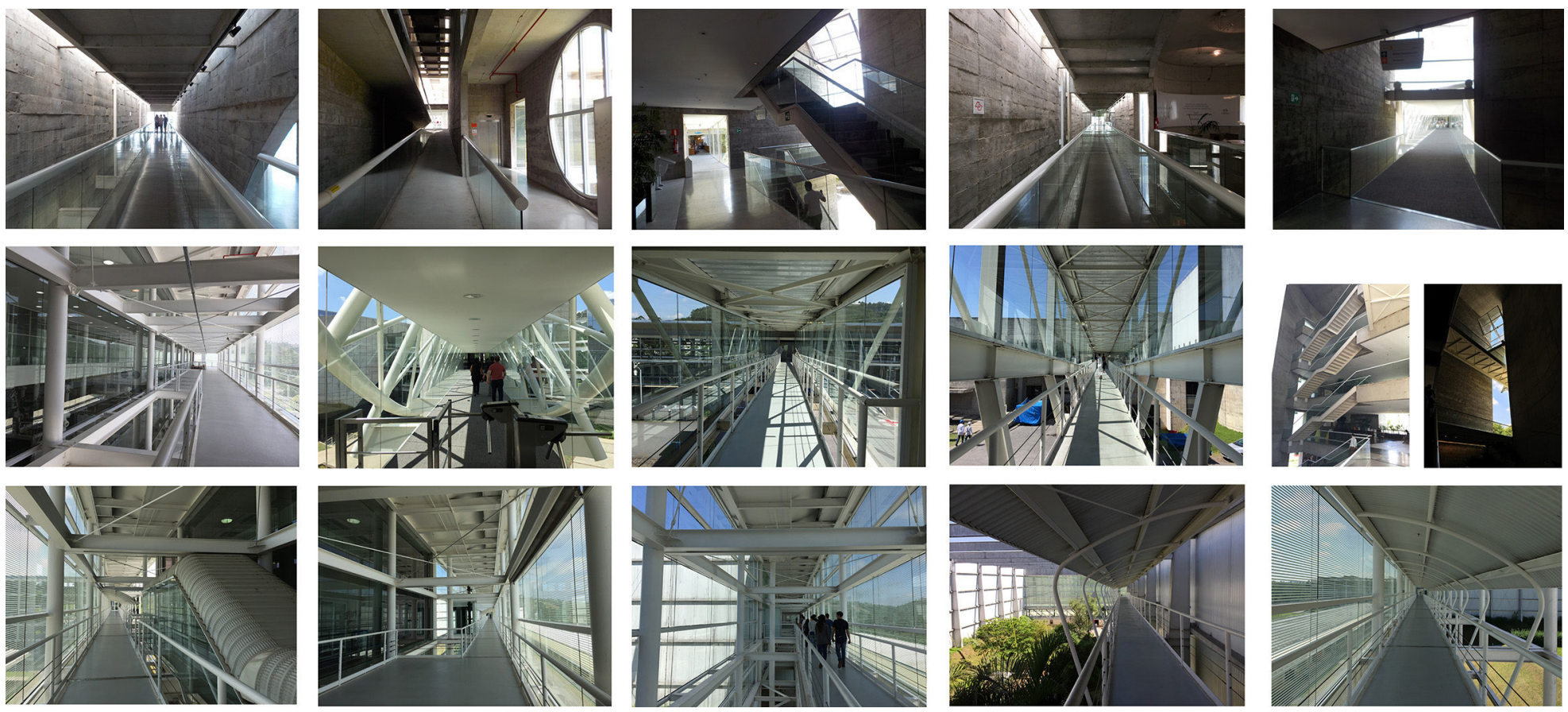

Figura 10: Fotos internas dos elementos de circulação dos edifícios do Espaço Natura. Fonte: Fotos e montagem, Autor (2017).
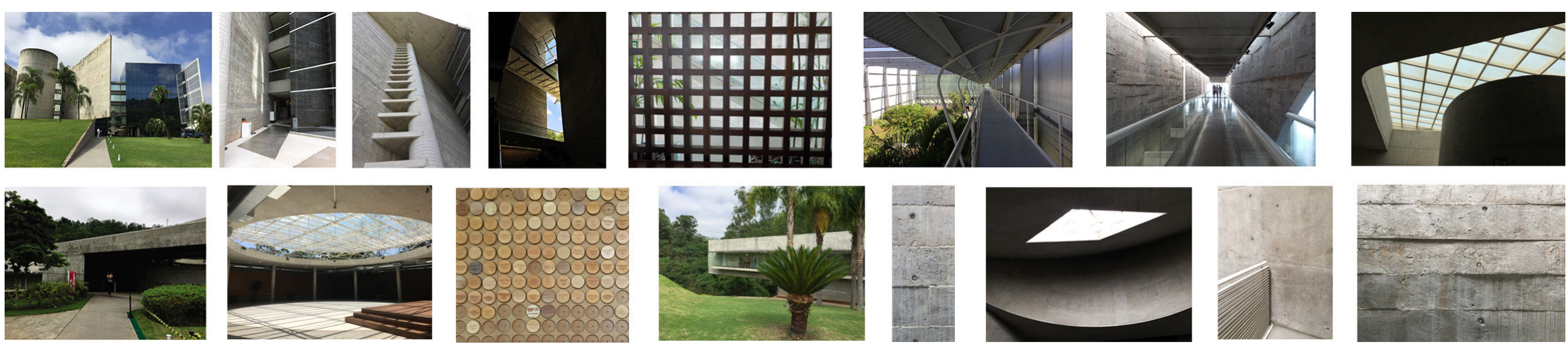

Figura 11: Fotos dos elementos materiais e imateriais que compõe os espaços e formas dos edifícios do Espaço Natura. Fonte: Fotos e montagem, Autor (2017). 


\section{O sistema de circulação como Estratégia Pro- jetual}

A partir da análise realizada identificamos que uma estratégia projetual e compositiva do arquiteto foi organizar o programa de necessidades em vários edifícios com formas diferentes, para assim destacar funcional e formalmente a circulação. Esta estratégia qualifica e enaltece as formas e a composição, além de conferir legibilidade à circulação. $O$ destaque dado aos elementos de circulação valoriza este sistema como um item do programa, ao mesmo tempo em que valoriza cada ambiente com suas especificidades, e o espaço entre estes ambientes, valoriza os pontos focais, suas visuais e enquadramentos criados neste percurso.

Adotando a categorização de Ching para analisar o movimento no espaço-tempo, verificamos as quatro etapas principais dos espaços da Natura:

1. Aproximação, entrada. Configuração do caminho e acesso: caminhos desenhados com acessos discretos;

2. Sequência de espaços: Organizados de modo a criar surpresas, sugerir visuais internas e externas, estimular a sensação e percepção por meio de vários elementos;

3. Composição com elementos materiais e imateriais como luz natural, vistas, tato, audição e olfato (percepção).
Apresentamos desenhos de estudo que destacam as estratégias projetuais do arquiteto para o Espaço Natura, que estão diretamente relacionadas com o sistema de circulação, que é composto por caminhos, corredores, passarelas, pontes, conexões, escadas, rampas, acessos, entre outros elementos (Figura 12).

O programa foi organizado em edifícios autônomos e interdependentes. A circulação horizontal é destacada entre estes edifícios de modo a criar visuais da paisagem circundante e dos edifícios, e descobertas. Os edifícios que estão lado a lado também têm a circulação que os conecta destacada com fechamentos em vidro, permitindo que o usuário ao caminhar tenha visuais da paisagem, valorizando o espaço "entre" e a experiência espacial do usuário. A composição organizada desta maneira valoriza as formas, materiais, seus contrastes como brilho e opacidade

A circulação horizontal é destacada dos ambientes, de modo a fazer o usuário perceber e valorizar o percurso e suas possibilidades sensoriais e perceptivas, além das visuais, pontos focais e descobertas. Dentro destas variações de estratégias projetuais também se verifica a organização da circulação de modo a criar os percursos longos voltados para paisagens que criam ao usuário a sensação de conforto e proximidade da natureza (Figuras 13 e 14). 

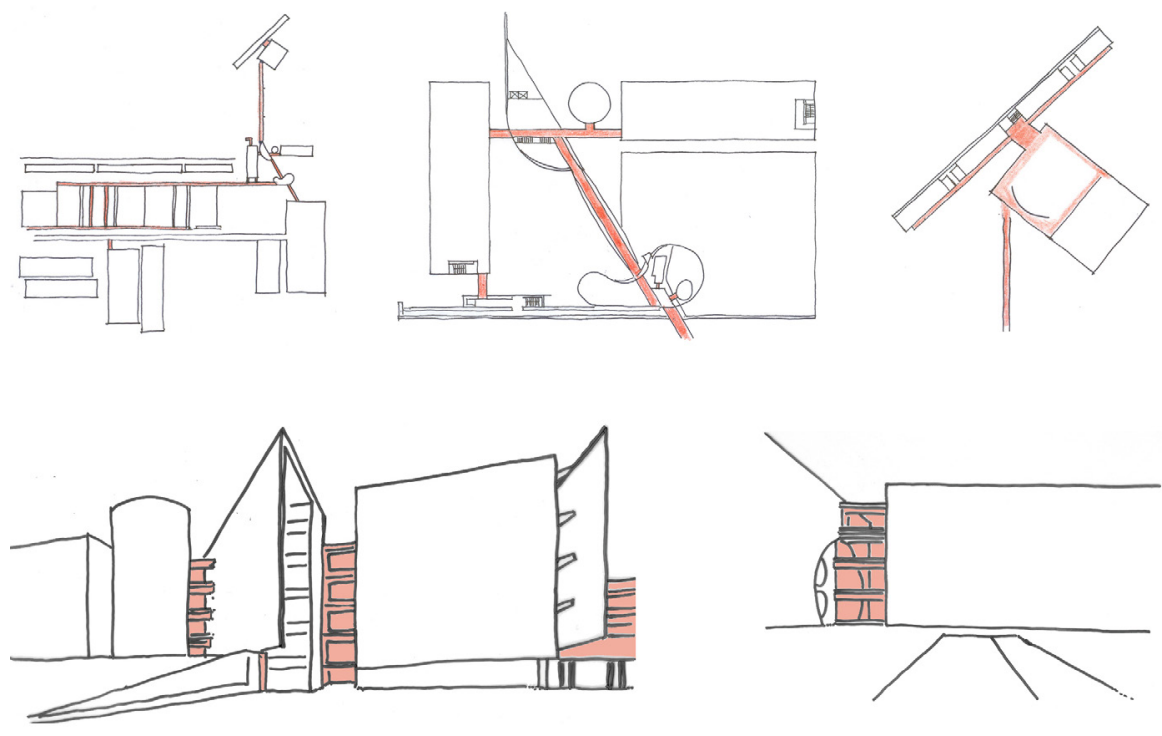

Figura 12: Desenhos de análise das estratégias projetuais e circulação em implantação e visuais do Espaço Natura. Fonte: Autor (2018).
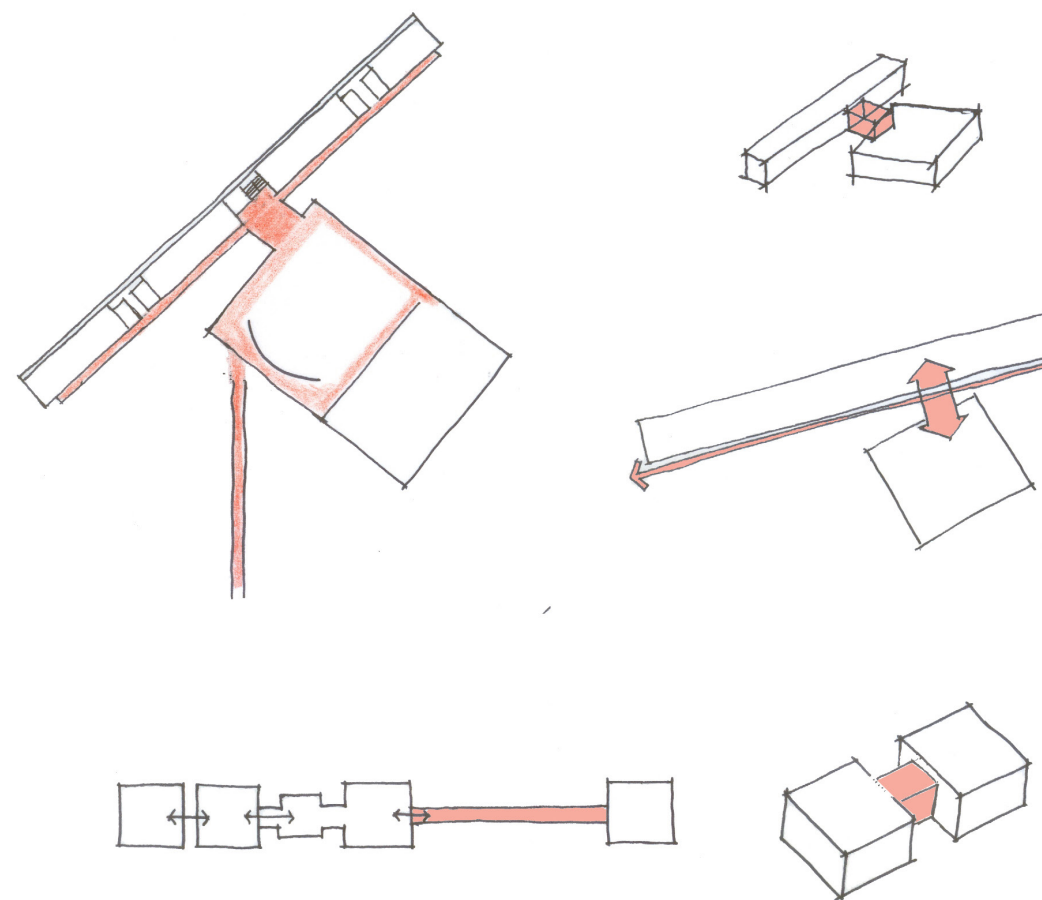

Figura 13: Desenhos de análise das estratégias projetuais em circulação no Espaço Natura. Fonte: Autor (2018).

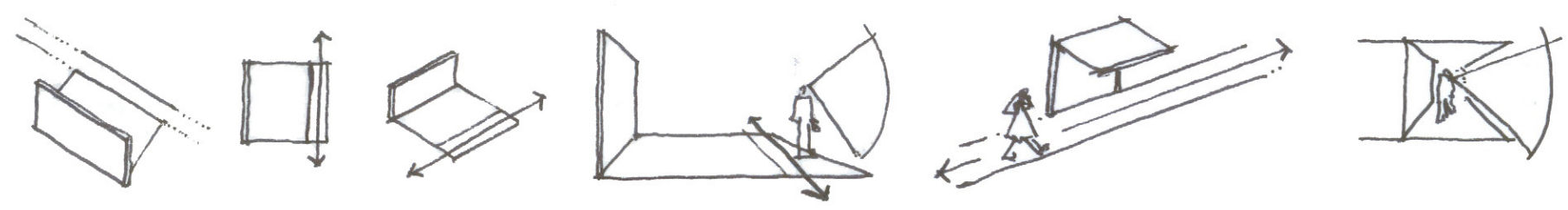

Figura 14: Desenhos de análise das estratégias projetuais em circulação no Espaço Natura. Fonte: Autor (2018). 


\section{Apontamentos Finais}

Este texto oferece uma análise interpretativa de um projeto industrial de grande importância, a partir da abordagem original do sistema de circulação em arquitetura.

A partir da análise deste projeto, é possível afirmar que o sistema de circulação adotado corresponde as intenções declaradas pelo próprio arquiteto: criar uma arquitetura que cause surpresas e descobertas, com espaços abertos e espaços fechados, onde o percurso desperta sensações, com vários elementos, materiais e imateriais, que participam deste espaço. Logo percebe-se que a sucessão de espaços e ambientes fazem com que o usuário descubra a arquitetura, aos poucos, numa alternância entre ambientes de transição e permanência, de trabalho e inspiração, de encontros e meditação.

Acreditamos que este projeto tem maior relação com o modelo conceitual de percurso e abordagem do sistema de circulação da pós-modernidade, da descoberta do espaço quadro a quadro, do que com o modelo moderno, da promenade que oferece o domínio do espaço por completo. Podemos também estabelecer uma relação do conceito do percurso do Espaço Natura com a ideia do jardim japonês, que tem em sua essência o conceito do percurso como um aprendizado e motivo de conhecimento oferecido por experiên- cias, visuais e eventos no seu decorrer. Princípios de percepção espacial e visual, simplicidade, harmonia com o local permeiam os espaços. $\mathrm{O}$ importante não é apenas o visto, mas sim, o imaginado.

O jardim japonês é conhecido, entre outras características, por despertar nas pessoas que o apreciam, diferentes sensações. Os espaços interferem na percepção de cada indivíduo, como numa reflexão sobre a própria existência no mundo. Nada é casual ou banal. Todos os elementos, espaços, formas, visuais, materiais e estímulos aos sentidos são cuidadosamente pensados de maneira a criar condições para o individuo pensar, refletir, valorizar e imaginar.

A arquitetura de Loeb supera, e muito, o aspecto meramente funcional, apesar de ser extremamente bem resolvida neste aspecto e também no que diz respeito à construção. Há questões subjetivas que permeiam os espaços. O utópico, o simbólico e o metafórico estão presentes em sua arquitetura. Os elementos de circulação e conexão, como as passarelas, por exemplo, oferecem também uma interpretação simbólica de fazer unir, e ao mesmo tempo criar espaços internos e externos, valorizando o espaço "entre", o intervalo, o espaço para apreciar a natureza e o céu, o vazio e o silêncio. 
A partir da experiência decorrente dos percursos pelo Espaço Natura é possível afirmar que os espaços criados são frutos de uma grande sensibilidade e profunda reflexão. Um espaço sensível para celebração, reflexão e engrandecimento da arquitetura, ou seja, um espaço inspirador.

\section{Referências:}

CHING, Francis D.K. Architecture. Form, Space and Order. Fourth Edition. New York: Wiley, 2015.

CORBUSIER, Le. Mensagem aos estudantes de arquitetura. São Paulo: Martins Fontes, 2005.

DUDEQUE, Marco Cezar. Promenade Brasileira. Cadernos Pós. Cadernos de pós-graduação em arquitetura e urbanismo Mackenzie. v.17 n.1 jan./jul. 2017. Disponível em: http://editorarevistas.mackenzie.br/index.php/cpgau/article/ view/2017.1\%20Dudeque. Acesso em 2018.

GOLDSCHMIDT, Gabriela; KLEVITSKY, Ekaterina. Graphic Representation as Reconstructive Memory: Stirling's German Museum Projects. In: GOLDSCHMIDT, Gabriela; PORTER, William L. Design Representation. London: Springer-verlag, 2004. p. 37-61.
KOOLHAAS, Rem. Rem Koolhaas. Barcelona: Quadernas d'Architectura i Urbanisme, 1990.

KOOLHAAS, Rem. Tres textos sobre a cidade. Barcelona: Gustavo Gilli, 2010.

MONEO, Rafael. Theoretical Anxiety and design strategies. In the work of eight contemporary architects. Cambridge: The MIT Press, 2004.

Revista Monolito. LoebCapote. Edição 25, 2015.

ROSSO, Silvana Maria. Roberto Loeb: arquiteto. São Paulo: BEI Comunicação, 2011.

SNYDER, James; CATANESE, Anthony. Introduction to architecture. New York: McGrawHill, 1979.

Souza Lima, Mirian Keiko Ito Rovo de. A experiência do "passeio arquitetônico" nas obras de Severiano Porto. ArqUrb, n. 12, 2014. Disponível em: http://www.usjt.br/arq.urb/numero-12/3-miriam-souza-lima.pdf. Acesso em 2018.

TAGLIARI, Ana. Modelos conceituais de percurso e circulação no projeto de arquitetura. Revista $5 \%$ Arquitetura + Arte, São Paulo, ano 13, volume 1, número 16, 2018.

ZEVI, Bruno. Saber ver a arquitetura. São Paulo: Martins Fontes, 1992. 


\section{Documentário}

Roberto Loeb. SESC TV

\section{Entrevista}

LOEB, Roberto. Entrevista a Marcelo Bratke. Programa Alma Brasileira. Rádio Cultura FM, 2018.

\section{Site}

http://www.loebcapote.com/

\section{Agradecimentos}

À equipe que nos recepcionou e guiou na visita ao Espaço Natura em novembro de 2017. Ao CNPq pelo auxílio financeiro à pesquisa 